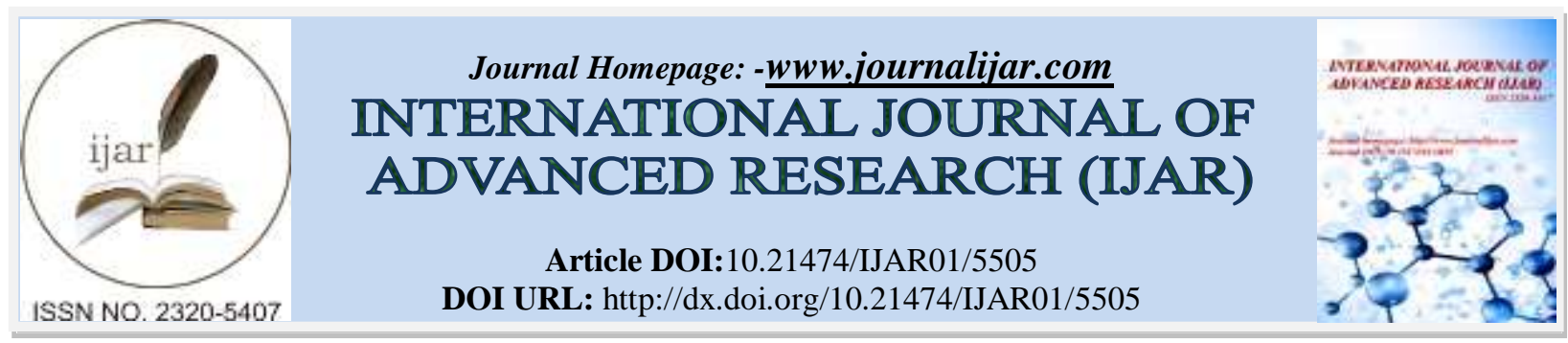

RESEARCH ARTICLE

\title{
OXIDATIVE BALANCE IN BRAIN AFTER EXPOSURE TO ARSENIC IN EX VIVO AND IN VIVO MODELS.
}

\section{Julián G Bonetto ${ }^{1,2}$, Edda Villaamil-Lepori ${ }^{3}$ and "Susana Puntarulo ${ }^{1,2}$.}

1. Universidad de Buenos Aires. Facultad de Farmacia y Bioquímica, Fisicoquímica. Buenos Aires, Argentina.

2. CONICET-Universidad de Buenos Aires. Instituto de Bioquímica y Medicina Molecular (IBIMOL). Buenos Aires, Argentina.

3. Universidad de Buenos Aires. Facultad de Farmacia y Bioquímica, Toxicología y Química Legal. Buenos Aires, Argentina.

\section{Manuscript Info}

\section{Manuscript History}

Received: 01 August 2017

Final Accepted: 03 September 2017

Published: October 2017

Key words:

Antioxidants, Arsenic, Brain, EPR

Detection, Oxidative Stress Ratios.

\begin{abstract}
The hypothesis of this work was that radical generation after exposure to As may contribute to its toxic effects in the brain tissues. Oxidative status of brain was studied, both using ex vivo and in vivo protocols of exposure to the toxic. The generation rate of lipid radicals ( $\left.\mathrm{LR}^{\bullet}\right)$, and ascorbyl radical $\left(\mathrm{A}^{\bullet}\right)$ content, were measured by Electron Paramagnetic Resonance (EPR). In the ex vivo model control brain homogenates were exposed to As, and a 2-fold increase was detected in the $\mathrm{LR}^{\bullet}$ generation rate, with no changes in $\mathrm{A}^{\bullet}$ radical content. A significant decrease of $33 \%$ and $30 \%$ in the content of glutathione (GSH) was measured after exposure to 3.3 and $4.0 \mathrm{pmol} \mathrm{As} / \mathrm{mg} \mathrm{FW}$, respectively. In the in vivo model, As was ip injected to rats and the rate of generation of $\mathrm{LR}^{\bullet}$ by homogenates of brain tissue, was increased by 81 and $122 \%$, as compared to control animals after the injection of 3.0 and $5.8 \mathrm{mg}$ $\mathrm{As} / \mathrm{kg}$, respectively. Neither GSH, nor $\alpha$-tocopherol $(\alpha-\mathrm{T})$ nor ascorbate $\left(\mathrm{AH}^{-}\right)$content was affected in As-treated rats, as compared to the values from control animals. The $\mathrm{LR}^{\bullet} / \alpha-\mathrm{T}$ content ratio was significantly increased in As-treated animals as compared to control brains. The $\mathrm{A}^{\bullet} / \mathrm{AH}^{-}$content ratio was not affected by As exposure. The content of total $\mathrm{Fe}$ showed non-significant differences between control and rat brains after $24 \mathrm{~h}$ of As administration. The data presented here showed new evidence on the generation of specific radical species by As treatment employing EPR methodologies in both, ex vivo and in vivo models. The data suggested the triggering of different pathways leading to some reactive species generation may occur accordingly to the via As reaches the brain, even when the same concentration of the toxic was achieved by the tissues.
\end{abstract}

Copy Right, IJAR, 2017. All rights reserved.

\section{Introduction:}

Arsenic (As) is a metalloid element, and its environmental behavior and metabolism are like the physicochemical characteristics of both metal and non-metal elements (Bonetto et al., 2014). As induces health effects in mammals, 
including cancer, cardiovascular disorders, and metabolic disease in humans (Jomova et al., 2011). Although the toxic and carcinogenic effects on humans exposed to As have been well documented in several tissues, such as liver, blood, kidney and spleen, only a few of them included the brain (Bonetto et al., 2014). As is mainly metabolized in liver by repetitive reduction and oxidative methylation. The arsenic methyltransferase (AS3MT) (+3 oxidation state) (Lin et al., 2002) and an independent minor AS3MT methylation pathway (Drobna et al., 2006) are the suggested main pathways of As metabolism. However, the role of other putative metabolic routes, including free radical reactions, is still under debate. Potential modes of action have been proposed, such as cytotoxicity and regenerative repair, formation of reactive oxygen species (ROS) resulting in oxidative stress and DNA damage, impaired DNA repair, dysregulation of signaling pathways that control the fate of cells (cycle progression, proliferation, differentiation, and apoptosis), and perturbations of gene structure (National Research Council. National Academy of Sciences, 2013).

ROS include superoxide anion $\left(\mathrm{O}_{2}^{-}\right)$, hydroxyl radical $\left({ }^{\bullet} \mathrm{OH}\right)$, hydrogen peroxide $\left(\mathrm{H}_{2} \mathrm{O}_{2}\right)$, singlet oxygen $\left({ }^{1} \mathrm{O}_{2}\right)$, and peroxyl radicals $\left(\mathrm{ROO}^{\circ}\right)$. The production of ROS in cellular and extracellular systems should be tightly controlled since they are highly reactive oxidants and mainly regarded as hazardous species. However, recently it has been recognized the importance of radical species in cellular signaling and in the maintenance of homeostatic conditions (Gonzalez et al., 2012). To be able to maintain dangerous reactive species at low steady state concentrations, the presence of many components is required to act as an adequate antioxidant defense system. The mechanisms for the action of these antioxidants involve three levels: (1) deactivation of reactive species by either enzymatic (e.g. catalase, CAT; and superoxide dismutase, SOD) or non-enzymatic compounds, both hydrophilic (e.g. gluthathione, GSH and ascorbate, $\mathrm{AH}^{-}$) and lipophilic (e.g. $\alpha$-tocopherol, $\alpha$-T) compounds; (2) prevention of radical formation (Halliwell, 1994), such as by ferritin (Ft) action chelating Fe; and (3) repair of already performed damage, such as by the activity of DNA repairing enzymes (Halliwell, 1994). Zamora et al. (2014) examined the capacity of trivalent arsenic species arsenous acid (iAs(III)), monomethylarsonous acid (MMA(III)), and dimethylarsinous acid (DMA(III)) to generate ROS through a theoretical analysis of their structures, redox properties, and their reactivities to various ROS using a density functional theory approach and by employing electron paramagnetic resonance (EPR) techniques. Spin trapping studies showed a higher propensity for methylated arsenicals to generate radicals than iAs(III) upon treatment with $\mathrm{H}_{2} \mathrm{O}_{2}$. However, in the presence of $\mathrm{Fe}$ (II, III), all showed radical generation where MMA(III) gave predominantly C-centered adducts, while acidified iAs(III) and DMA(III) gave primarily HOadducts, and their formation was affected in the presence of SOD suggesting a As(III)-OO/OOH radical intermediate. Although these EPR studies concluded that the As toxicity pathway might involve ROS, there are not EPR reports using biological systems. Recently, oxidative stress ratios (damage/protection indexes), such as ascorbyl radical $\left(\mathrm{A}^{\bullet}\right) / \mathrm{AH}^{-}$content, and lipid radical $\left(\mathrm{LR}^{\bullet}\right) / \alpha-\mathrm{T}$ content have been described as useful tools for stress diagnosis (Malanga et al., 2009; González et al., 2013).

Experimental results have shown that As exposure of some cell lines generated $\mathrm{O}_{2}{ }^{-}$and $\mathrm{H}_{2} \mathrm{O}_{2}$ (Garcia-Chavez et al., 2003; Jing et al., 1999; Wang et al., 1996). It was described that arsenite inhibits glutathione reductase (GR) activity and diminishes the intracellular level of GSH (Thomas et al., 2001). Bharti et al. (2012) reported that rats exposed to As showed an increase in lipid peroxidation in brain with a significant decrease in the GSH level and in the activities of CAT, SOD, glutathione peroxidase (GPx), and GR activities. Rao and Avani (2004) and Chaudhuri et al. (1999) also reported increased neurotoxic oxidative stress in mouse brains after oral administration of arsenic trioxide. Aung et al. (2013) in an in vitro study suggested the induction of neural apoptosis since neurite outgrowth was suppressed by sodium arsenite. Deficits in spatial memory and in executive and motor function were shown in animal studies (Tolins et al., 2014). Also, low to moderate concentrations of arsenic, were associated to neurologic deficits, particularly detected in children by IQ tests (Wasserman et al., 2014). The mechanisms appear related to oxidative stress-induced apoptosis and effects on neurotransmitters (National Research Council. National Academy of Sciences, 2013). Moreover, arsenicals can release Fe by the activation of the enzyme heme-oxygenase (HO-1) (Albores et al., 1989). Negishi et al. (2013) reported that the adverse effects of exposure to diphenyl arsenic acid (DPAA) in the drinking water during development could be due to an increase in HO-1 in the cerebellar astrocytes. Previously, Ahmad et al. (2000) suggested the direct reduction of Ft Fe by dimethyl arsenic acid (DMAIII) as the predominant pathway, and that DMAIII and $\mathrm{AH}^{-}$-mediated Fe-release from $\mathrm{Ft}$ (not via $\mathrm{O}_{2}^{-}$) also may be a significant route in vivo. The hypothesis of this work was that radical generation induced by the exposure to As may contribute to its toxic effects in the brain tissues, even in the absence of previous metabolism of As by the liver. To fulfil this goal, oxidative status of brain was studied, by employing both ex vivo and in vivo protocols of exposure to the toxic, with direct detection of radical species using EPR. 


\section{Material and Methods: Experimental design:}

The School of Pharmacy and Biochemistry, University of Buenos Aires, provided the male Albino Wistar rats (200 $\pm 20 \mathrm{~g}$ ) used in this study through the Animal Facility. The animals were housed under standard conditions of light, temperature and humidity with unlimited access to water and food. The rats were injected intraperitoneally (ip) with one doses of sodium arsenite $\left(\mathrm{NaAsO}_{2}\right)$ of 1 to $5.8 \mathrm{mg} \mathrm{As} / \mathrm{kg}$ body weight. Saline solution was employed to sham-ip injected control rats. Brains from control and As-treated animals were excised from euthanized animals in a $\mathrm{CO}_{2}$ chamber, and rinsed in cold saline solution. Except where noted otherwise, the samples were freeze-clamped immediately following removal and stored under liquid $\mathrm{N}_{2}$ until used. Whole blood was taken by cardiac punction. Experimental animal protocols and animal procedures were in agreement with the Guide for the Care and Use of Laboratory Animals (1985), and were carried out according to the principles and directives of the European Communities Council Directives (1986). The procedures also received approval from the Institutional Animal Care and Use Committee-School of Pharmacy and Biochemistry (CICUAL-FFyB, RES N ${ }^{\circ} 1037$ ).

\section{As content:}

The quantification of As species $\left[\mathrm{As}^{\mathrm{V}}+\mathrm{As}^{\mathrm{III}}+\operatorname{acidmonometilarsónico~(MMA)~+~dimethyl~arsinic~acid~(DMA)]~}\right.$ content in brain and whole blood was performed by hydride generation-atomic absorption spectrometry (HG-AAS), after dry mineralization. A hydride generator VGA77 and an atomic absorption spectrometer Varian Spectra AA 200 were employed according to Navoni et al. (2010).

\section{Detection of $\mathrm{LR}^{\bullet}$ generation rate by EPR:}

$\mathrm{LR}^{\bullet}$ generation rate was detected by a spin trapping technique using $\mathrm{N}$-t-butyl- $\alpha$-phenyl nitrone (PBN) or N-tertButyl-alpha-(4-pyridyl-1-oxide) nitrone (POBN) depending of the experimental protocol. In the in vivo experiments, a $40 \mathrm{mM}$ PBN stock solution was prepared in dimethyl sulfoxide (DMSO) immediately prior to use. Brain tissue was homogenized in DMSO-PBN (stock solution) in a concentration of $25 \mathrm{mg} / \mathrm{ml}$, incubated for $30 \mathrm{~min}$ and immediately transferred to a Pasteur pipette for $\mathrm{LR}^{\bullet}$ detection. In the ex vivo experiments, brain tissue was homogenized in $100 \mathrm{mM}$ potassium phosphate buffer ( $\mathrm{pH}$ 7.4) with $40 \mathrm{mM}$ of POBN in a concentration of 75 $\mathrm{mg} / \mathrm{ml}$, incubated at $37^{\circ} \mathrm{C}$ in presence of As between 1.3 and $4 \mathrm{pmol} \mathrm{As} / \mathrm{g} \mathrm{FW}$ of tissue, and transferred to a Pasteur pipette for $\mathrm{LR}^{\bullet}$ detection. Instrument settings were as follows: modulation frequency $50 \mathrm{kHz}$, microwave power 10 $\mathrm{mW}$, microwave frequency $9.75 \mathrm{GHz}$, centered field $3487 \mathrm{G}$, time constant $81.92 \mathrm{~ms}$, modulation amplitude $1.20 \mathrm{G}$ and sweep width $100 \mathrm{G}$, according to Lai et al. (1986). Quantification of the spin adduct was performed using TEMPO introduced into the same sample cell used for spin trapping. EPR spectra for both sample and TEMPO solutions were recorded at the same spectrometer settings and the first derivative EPR spectra were double integrated to obtain the area intensity, then the concentration of spin adduct was calculated according to Kotake et al. (1996).

\section{Reduced GSH content:}

The content of GSH in brain exposed to As was performed according to Rodriguez-Ariza et al. (1994) with modifications. Brain homogenates $(20 \% \mathrm{p} / \mathrm{v})$ were prepared in $1 \mathrm{M}$ perchloric acid and $2 \mathrm{mM}$ EDTA soon after isolation of the tissues in the in vivo model. For the ex vivo model, the homogenate from control brain (20\% p/v) in

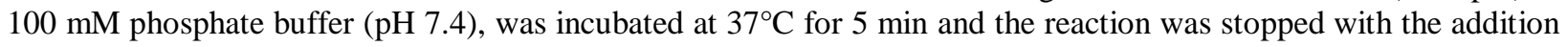
of $1 \mathrm{M}$ perchloric acid and $2 \mathrm{mM}$ EDTA. Then reaction mixture was filtered at $10,000 \mathrm{~g}$ for $5 \mathrm{~min}$ at $4^{\circ} \mathrm{C}$. The supernatant was recovered and filtered using $0.2 \mu \mathrm{m}$ filters. The samples were kept at $-80^{\circ} \mathrm{C}$ for quantification by HPLC-EQ assay employing commercially available standard GSH.

\section{Detection of $\mathrm{A}^{\bullet}$ content:}

A Bruker EMX plus $\mathrm{X}$ band spectrometer was used for $\mathrm{A}^{\bullet}$ measurements. Brain tissue was homogenized in dimethyl sulfoxide (DMSO) in a concentration of $25 \mathrm{mg} / \mathrm{ml}$ and the spectra were immediately scanned under the following conditions: $50 \mathrm{kHz}$ field modulation, room temperature, microwave power $10 \mathrm{~mW}$, modulation amplitude $1 \mathrm{G}$, time constant $655 \mathrm{~ms}$, receiver gain $1 \times 10^{5}$, microwave frequency $9.81 \mathrm{GHz}$, and scan rate $0.18 \mathrm{G} / \mathrm{s}$ (Piloni et al., 2013). Quantification was performed as previously described, according to Kotake et al. (1996).

\section{AH' content:}

The content of $\mathrm{AH}^{-}$, was measured by reverse-phase HPLC-EQ. The samples were homogenized in metaphosphoric acid (10\%, w/v) according to Kutnink et al. (1987). 


\section{$\alpha-T$ content:}

The content of $\alpha$ - T in brain tissues was quantified by reverse-phase HPLC-EQ with a Perkin Elmer 250 pump and a ESA Cuolochem II electrochemical detector, at an applied oxidation potential of $0.6 \mathrm{~V}$ according to Desai (1984). D,L- $\alpha$-Tocopherol (Sigma) were used as standards.

\section{Total Fe content:}

The whole brain was dried in an oven at $60^{\circ} \mathrm{C}$ until constant weight, were mineralized in $\mathrm{HNO}_{3}$ according to Laurie et al. (1991). Fe concentration was spectrophotometrically determined after reduction with thioglycolic acid measuring the absorbance at $\lambda=535 \mathrm{~nm}$ in the presence of bathophenanthroline according to Brumby and Massey (1967).

\section{Statistical analyses:}

Data in the text and tables are expressed as mean values \pm standard error of the mean (S.E.M.). Statistical tests were carried out using Graph Pad Prism 6, Unpaired Student's t-test or one-way ANOVA with Dunnett's post-test, depending on the experimental protocol. The level of statistical significance adopted was $\mathrm{p}<0.05$.

\section{Results:}

The ex vivo effect of As over brain tissues was studied, by EPR, assessing the generation rate of $\mathrm{LR}^{\bullet}$ as a measurement of lipid peroxidation. $\mathrm{LR}^{\bullet}$ combined with the spin trap POBN resulting in adducts that gave a characteristic EPR spectrum with hyperfine coupling constants of $\mathrm{a}_{\mathrm{N}}=15.8 \mathrm{G}$ and $\mathrm{a}_{\mathrm{H}}=2.6 \mathrm{G}($ Fig. $1 \mathrm{~A})$, in agreement with computer spectral simulated signals obtained using those parameters. Even though these constants could be assigned to $\mathrm{LR}^{\circ}$, spin trapping studies cannot readily distinguish between peroxyl, alcohoxyl and alkyl adducts, owing to the similarity of the corresponding coupling constants (Buettner, 1987). Control brain homogenates were exposed to 1.3-4 pmolAs/mg FW, and an approximately 2-fold increase in the $\mathrm{LR}^{\bullet}$ generation rate was recorded (Fig. 1B).

A

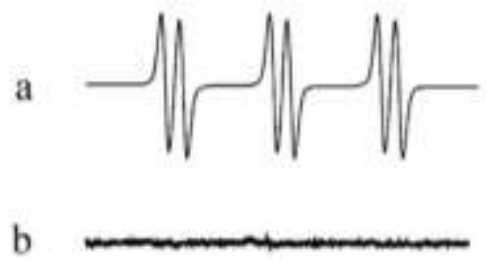

c
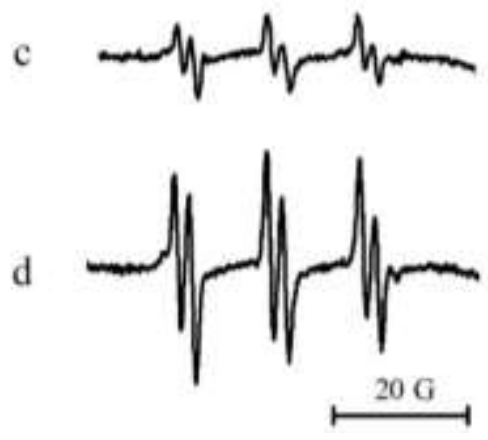

B

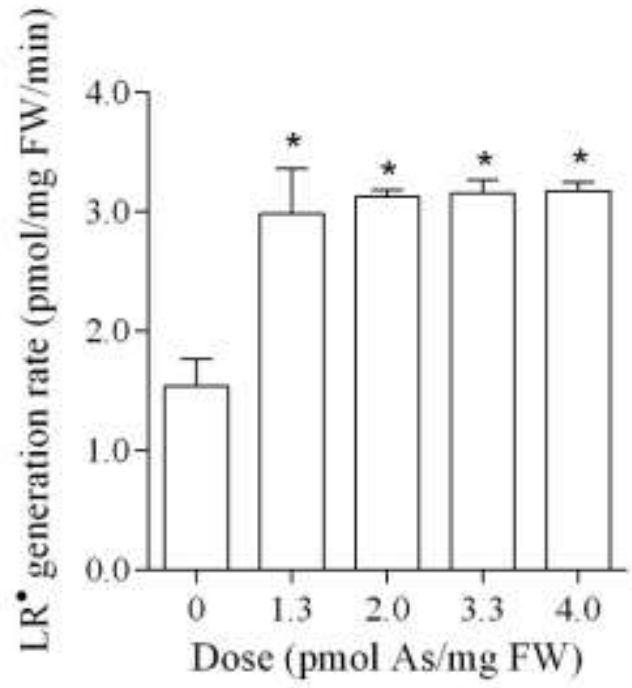

*significantly different from values in homogenates non-exposed to As. Student's T-test, $\mathrm{p}<0.05$.

Figure 1: $\mathrm{LR}^{\bullet}$ generation rate in brain homogenates after exposure to As ex vivo. A. EPR signal for $\mathrm{LR}^{\bullet}$ in control and rat brain homogenates exposed to As, (a) computer simulated-spectrum employing the following spectral parameters: $\mathrm{g}=2.005$ and $\mathrm{a}_{H}=1.8 \mathrm{G}$, (b) POBN alone, (c) control rat brain, (d) rat brain homogenate exposed to 2.0 $\mathrm{pmol} \mathrm{As} / \mathrm{mg} \mathrm{FW}$ in the presence of $40 \mathrm{mM}$ POBN in buffer. B. Quantification of $\mathrm{LR}^{\bullet}$ generation rate in rat brains after exposure to several As concentrations. 
Brain homogenates from control rats showed the typical EPR spectrum of $\mathrm{A}^{\bullet}$, with the characteristic two lines at $\mathrm{g}=$ 2.005 and $\mathrm{a}_{\mathrm{H}+}=1.8 \mathrm{G}$ (Fig. $2 \mathrm{~A}$ ). The ex vivo exposure to 1.3 to 4.0 pmolAs/mg FW during 5 min did not significantly affect the generation rate of $\mathrm{A}^{\bullet}$ by brain samples (Fig. 2B).

A

a

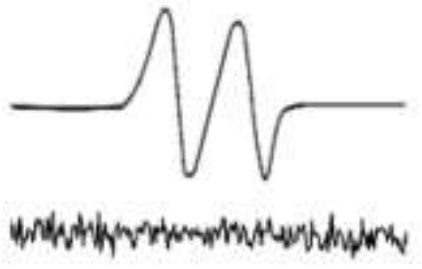

c
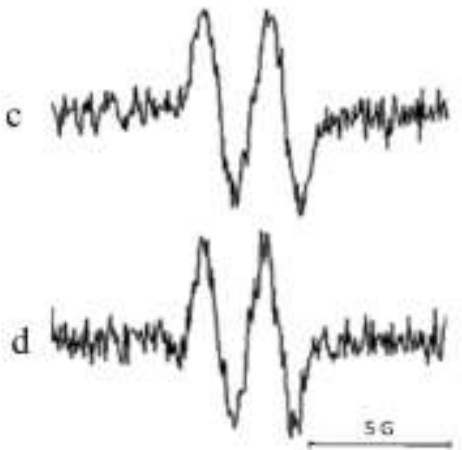

B

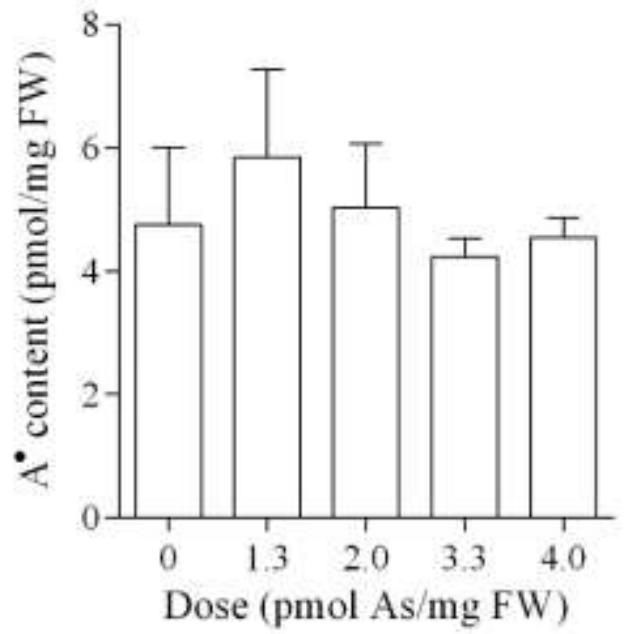

Figure 2: $\mathrm{A}^{\bullet}$ content in brain homogenates after exposure to As ex vivo. A. EPR signal for $\mathrm{A}^{\bullet}$ in control rat brain homogenates exposed to As during $5 \mathrm{~min}$, (a) computer simulated-spectrum employing the following spectral parameters: $\mathrm{g}=2.005$ and $\mathrm{a}_{H}=1.8 \mathrm{G}$, (b) DMSO alone, (c) control rat brain homogenate, (d) rat brain homogenate exposed to $3.3 \mathrm{pmol} \mathrm{As} / \mathrm{mg} \mathrm{FW}$. B. Quantification of $\mathrm{A}^{\bullet}$ generation rate in rat brains after exposure to several As concentrations.

A dose-dependent significant decrease of 33\% and 30\% in the content of the antioxidant GSH was measured after exposure to 3.3 and 4.0 pmolAs/mg FW, respectively (Fig. 3).

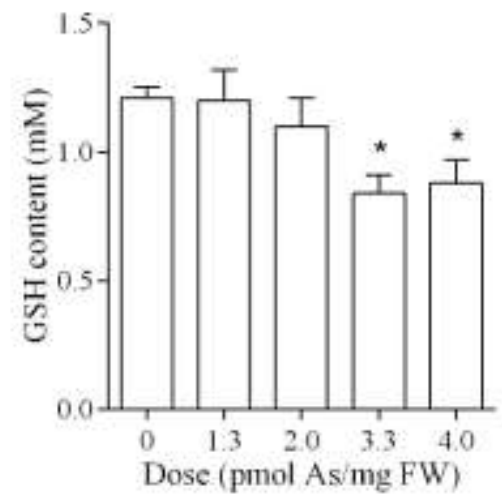

*significantly different from values in homogenates non-exposed to As. Student's T-test, $\mathrm{p}<0.05$

Figure 3: GSH quantification in brain homogenates after exposure to different doses of As ex vivo.

Since As is mainly metabolized in liver by repetitive reduction and oxidative methylation (Bonetto et al., 2014), for the in vivo studies the As content, both in whole blood and brain, was measured after the ip injection of a single dose of As. In all the As concentration range studied no morphological damage was observed in liver tissue by employing histology with hematoxylin and eosin staining techniques (data not shown). The data in Fig 4A showed that As 
content reached its maximum value, in both compartments, after $24 \mathrm{~h}$ of the administration of the single dose of As. In both tissues, the As content depended on the administrated dose of As (Fig. 4B).

A

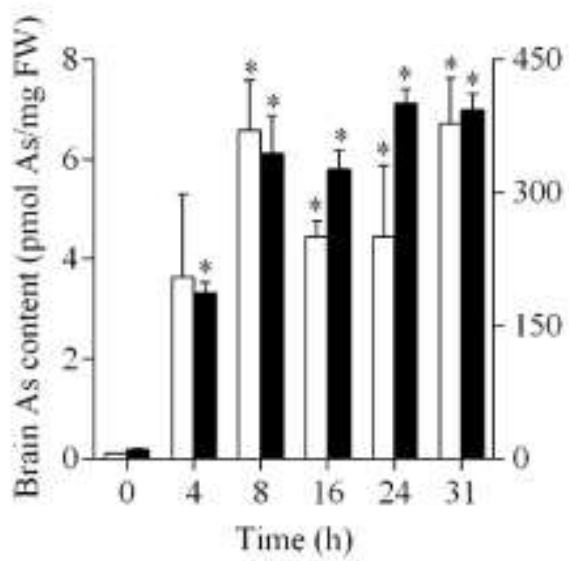

B

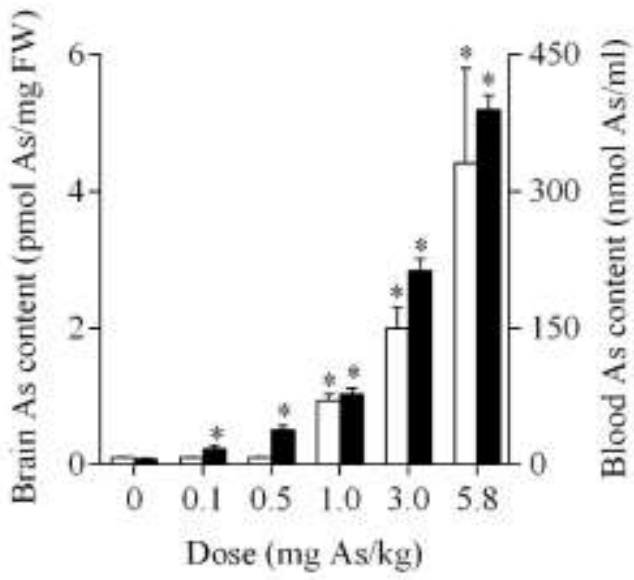

*significantly different from values in animals non-exposed to As. One way ANOVA with Dunnett's post-test, $\mathrm{p}<0.05$.

Figure 4: As content in rat blood and brain. A. Brain (white bars) and blood (black bars) content as a function of time after the administration of a single dose of $5.8 \mathrm{mg} \mathrm{As} / \mathrm{kg}$ body weight. B. Brain (white bars) and blood (black bars) content as a function of the doses of As administrated to the animals. Measurements were performed after $24 \mathrm{~h}$ of the ip injection of As.

Moreover, as it was seen after exposure to As in the ex vivo experiments, the rate of generation of $\mathrm{LR}^{\bullet}$ by homogenates of brain tissue excised $24 \mathrm{~h}$ after the As administration to the animals, was increased as compared to values observed in brain from control rats. Data in Figure 5 showed that the LR ${ }^{\bullet}$ generation rate in the brain was increased by 81 and $122 \%$, after the administration of 3.0 and $5.8 \mathrm{mg} \mathrm{As} / \mathrm{kg}$, respectively.

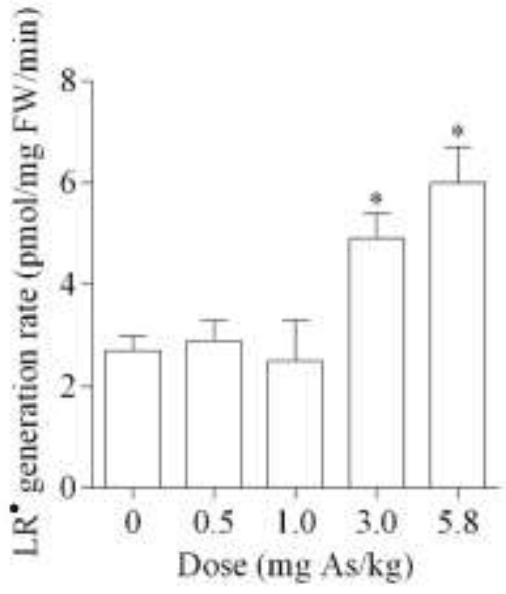

*significantly different from values in animals non-exposed to As. Student's t-test, $\mathrm{p}<0.05$.

Figure 5: $\mathrm{LR}^{\bullet}$ generation rate in brain homogenates after exposure to As in vivo. Quantification of $\mathrm{LR}^{\bullet}$ generation rate in rat brains excised after $24 \mathrm{~h}$ of exposure to several As doses. Brain homogenates were incubated in the presence of $40 \mathrm{mM}$ PBN-DMSO for $30 \mathrm{~min}$. 
However, neither the content of GSH, nor $\alpha-\mathrm{T}_{\text {nor }} \mathrm{AH}^{-}$in brain tissues from animals receiving $5.8 \mathrm{mg} \mathrm{As} / \mathrm{kg}$ was significantly affected, as compared to the values from control animals (Table 1).

Table 1

\begin{tabular}{lllll}
\hline & $\begin{array}{l}\alpha \text {-T content } \\
(\mathrm{pmol} / \mathrm{mg} \mathrm{FW})\end{array}$ & $\begin{array}{l}\mathrm{AH}^{-} \text {content } \\
(\mathrm{pmol} / \mathrm{mg} \mathrm{FW})\end{array}$ & $\begin{array}{l}\text { GSH content } \\
(\mathrm{mM})\end{array}$ \\
\hline Control & & $11 \pm 1$ & $171 \pm 8$ & $1.9 \pm 0.1$ \\
As $(\mathrm{mg} / \mathrm{kg})$ & 1.0 & $13 \pm 1$ & $182 \pm 14$ & non-determined \\
& 3.0 & $12 \pm 1$ & $164 \pm 27$ & non-determined \\
& 5.8 & $12 \pm 1$ & $167 \pm 7$ & $2.0 \pm 0.1$
\end{tabular}

Measurements were performed after $24 \mathrm{~h}$ of the ip injection of As.

The $\mathrm{LR}^{\bullet} / \alpha$-T content ratio, considered as an indicator of the balance between free radical damage and antioxidant protection in the hydrophobic medium (Malanga et al., 2009), was significantly different between samples obtained from control and As-treated animals in a dose-dependent way (Fig. 6A). However, the $\mathrm{A}^{\bullet}$ content in brain samples from control rats was not significantly affected $24 \mathrm{~h}$ after As administration in any tested dose (Fig. 6B). The $\mathrm{A}^{\bullet} / \mathrm{AH}^{-}$content ratio, understood as an index of oxidative stress in the hydrophilic medium (González et al., 2013), was not significantly different between the obtained data in control and As-treated animals (Fig. 6B).

A

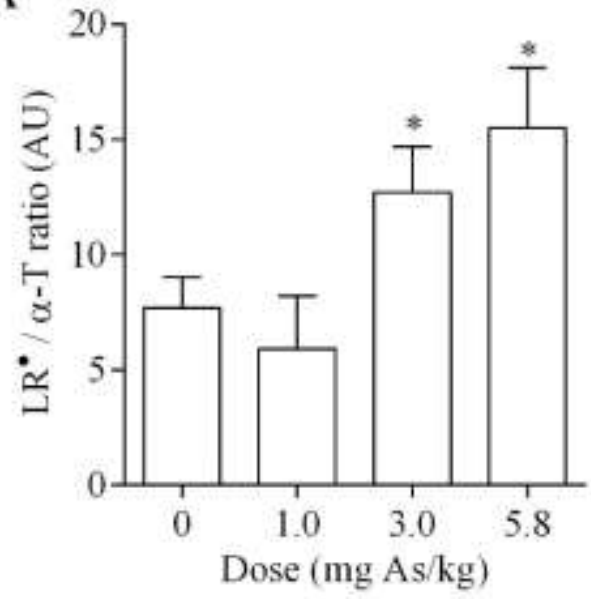

B

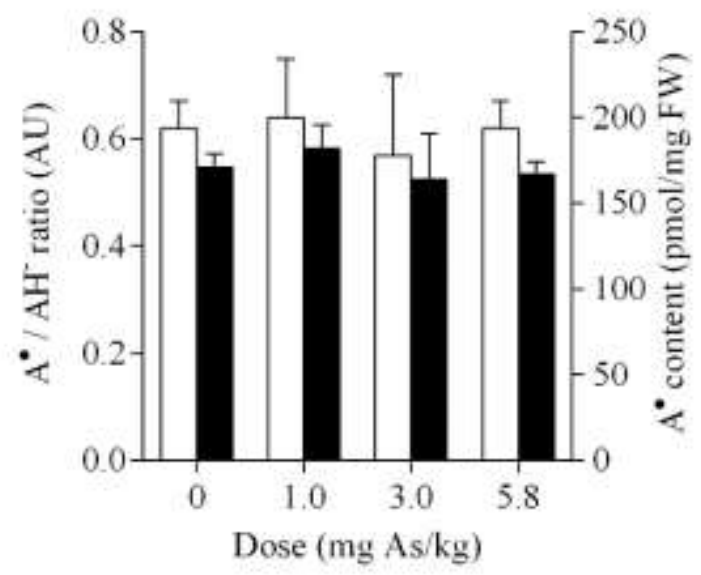

*significantly different from values in animals non-exposed to As. Student's t-test, $\mathrm{p}<0.05$

Figure 6: Oxidative balance in the lipophilic and hydrophilic environment in rat brain after exposure to As. A. $\mathrm{LR}^{\circ} / \alpha$-T content as a function of the doses of As administrated $24 \mathrm{~h}$ before the measurement. B. $\mathrm{A}^{\circ} / \mathrm{AH}^{-}$ratio (white bars) and ascorbyl radical content (black bars) as a function of the doses of As administrated $24 \mathrm{~h}$ before the measurement.

Since arsenicals can release $\mathrm{Fe}$, the content of total Fe was measured. No significant differences between brain homogenates from control and treated animals for $24 \mathrm{~h}$ with $5.8 \mathrm{mg} \mathrm{As} / \mathrm{kg} 24 \mathrm{~h}(1.4 \pm 0.2$ and $1.5 \pm 0.2 \mathrm{pmol} / \mathrm{mg}$ $\mathrm{FW}$, respectively) were seen.

\section{Discussion:}

Even though the main forms responsible for As toxicity, as compared to the pentavalent forms, are the highly toxic intermediate arsenicals monomethylarsonous acid (MMAIII) and DMAIII (Catalayud et al., 2013), As and ROS metabolisms may be closely associated. Several metabolic pathways were proposed for As-dependent oxidative 
damage to tissues. Yamanaka et al. (1989, 2009) postulated the formation of an oxidative stress promotor, a dimethylated As peroxide from DMA, the generation of dimethylarsenic $\left[\left(\mathrm{CH}_{3}\right)_{2} \mathrm{As}{ }^{\circ}\right]$ and dimethylarsenic peroxy radicals $\left[\left(\mathrm{CH}_{3}\right)_{2} \mathrm{AsOO}^{\circ}\right]$. However, up to now no experimental evidence was presented about the absolute requirement of the liver contribution to the formation of radical species by As exposure. Brain cells may be at particular risk for oxidative stress. The brain derives its energy almost exclusively from oxidative metabolism through the mitochondrial respiratory chain, and is relatively deficient in protective mechanisms compared to other tissues. It contains reduced quantities of CAT, GPx, GSH and $\alpha$-T than the liver or the kidney (Rodriguez et al., 2003), but Kharroubi et al. (2017) studying microglial BV-2 cells treated with sodium arsenate showed neurotoxic effects of high concentrations of $\mathrm{As}^{\mathrm{V}}$ by increased levels of mitochondrial complexes I, II, and IV, followed by increased $\mathrm{O}_{2}^{-}$generation. These authors suggested that $\mathrm{As}^{\mathrm{V}}$ triggered mitochondrial dysfunction, which may lead to defective oxidative phosphorylation subsequently causing mitochondrial oxidative damage, which in turn, induces an apoptotic mode of cell death with an alteration of plasma membrane integrity. This proposal is consistent with the results presented here. The rate of generation of $\mathrm{LR}^{\bullet}$, showed a compatible effect in vivo, as compared to the response seen in the ex vivo study. Moreover, the $\mathrm{LR} / \alpha-\mathrm{T}$ content ratio was significantly increased in the in vivo model, in agreement with the development of oxidative damage to membranes by the exposure to the toxic. Thus, it seems that liver processing of As is not a key factor for radical generation in brain at the lipophilic medium. The production of $\mathrm{A}^{\bullet}$, a resonance stabilized tricarbonyl species, is easily observable by EPR in aqueous solutions at room temperature since it is a quite stable radical with a biologic half-life of 30-60 min (Ahola et al., 2004). Homogenates of rat brain exposed ex vivo to As showed no changes in the content of $\mathrm{A}^{\bullet}$, and neither did the homogenates from in vivo animals exposed to As, as compared to control brain homogenates. Since the content of $\mathrm{A}^{\bullet}$ was not affected by the single doses of As in all the range of concentrations tested, the data from the ex vivo and in vivo studies suggested that the oxidative balance in the hydrophilic cellular environment was not affected by As exposure. Thus, in agreement with the response observed in the lipophilic medium, the nature of the protocol of administration of As does not seem to be directly involved as a factor for modifying the As-dependent radical generation. Moreover, $\mathrm{A}^{\bullet}$ signal intensity is a function of $\mathrm{pH}$, temperature, catalytic metal concentration, oxygen concentration and $\mathrm{AH}^{-}$concentration. Only when these variables can be controlled, the intensity of the EPR signal of the $\mathrm{A}^{\bullet}$ in steady-state concentration serves as a marker for the oxidative stress in a system (Buettner and Jurkiewicz, 1993). In intact biological systems it is very difficult to control all these variables, especially the total $\mathrm{AH}^{-}$content, which can be modified by the pro-oxidant conditions in a given cellular preparation. In such cases, the $\mathrm{A}^{\bullet}$ content is not applicable as oxidative stress indicator by itself, and the ratio $\mathrm{A}^{\bullet} / \mathrm{AH}^{-}$content should be used. The in vivo experiments reported here using EPR spectroscopy, in conjunction with HPLC detection of the $\mathrm{AH}^{-}$content, a powerful tool for detection of the initial stages of oxidative stress in the cellular hydrophilic compartment, agreed with the ex vivo experiments. The data reported here are consistent with the hypothesis that the liver is not absolutely required for causing these changes in the oxidative metabolism, either because the transformations to the active forms of As can be performed by the brain or that oxidative stress could be triggered directly by the inorganic As. Further studies are needed to clarify the mechanism(s), however these observations are the first indications in this regard. The tested doses of As employed in the ex vivo study were consistent with the As content achieved in brain $24 \mathrm{~h}$ after the administration of a single doses of As ( $5.8 \mathrm{mg} / \mathrm{mg} \mathrm{FW}$ brain). Moreover, achieving comparable content of As in brain by ex vivo and in vivo experiments allowed to exclude the effect of the As content when comparing the assays protocols used in the studying of the effect of As in the cellular redox balance. On the other hand, GSH metabolism seems to play a role in As toxicity. The conjugation of iAs ${ }^{\text {III }}$ with GSH has been described by Hayakawa et al. (2005) and Pastore et al. (2003). Since As interacts with thiol groups, it can be directly toxic by blocking essential sulfhydryl groups of protein and enzymes, such as succinic and pyruvate dehydrogenases (Aposhian, 1989), or by binding to free sulfhydryl groups of membrane proteins inducing a marked decrease of free sulfhydryl groups and altering the intracellular signaling mechanisms (Zhang et al., 2000). DMAG ${ }^{\mathrm{III}}$ was described to be reduced to a dimethylarsine by a GR and NADPH, and this product may react with molecular $\mathrm{O}_{2}$ to form dimethylarsine radical. Monomethylarsonic diglutathione (MMDG ${ }^{\mathrm{III}}$ ) was present in the reaction mixture (Hayakawa et al., 2005). Accordingly, the exposure to As in the ex vivo model studied here shown a significant decrease in the content of GSH in rat brain. Rezaei et al. (2017) showed that acute, but not chronic contact with As generates significant changes in the normal glucose tolerance pattern that may be due fundamentally to over production of ROS and oxidative stress, and is preventable by using $\mathrm{N}$-acetylcysteine, a thiol containing antioxidant. The data presented in this work is showing that not only the pattern of administration of As, but also the employment of an ex vivo or an in vivo acute contact could a be a key factor to generate a differential oxidative response. Thus, the data presented here, by comparing the effects of comparable doses of As administrated either $e x$ vivo or in vivo, suggested that even though oxidative stress is detected at the membrane level, the nature of the 
metabolic pathways triggered in the brain differs according to the exposure protocol in terms of GSH consumption. As is a worldwide environmental contaminant, which compromises immunity and causes various associated disorders. Soria et al. (2017) to further investigate its immune toxicity exposed rats to inorganic As ${ }^{\text {III }}$ in drinking water for 2 months, and then evaluated subsequent changes of redox enzyme responses in spleen parenchyma cells (splenocytes). Not only As-exposed splenocytes showed $\gamma$-glutamyltranspeptidase inhibition, peroxidase induction, and variable responses of nitric oxide synthase, but also established the impact of As bioaccumulation on metallic spatial homeostasis (including Fe content) in the spleen. These authors suggested that As disrupts biometaldependent immune pathways and redox homeostasis. The data presented here, however, showed that Fe total content was not modified by As administration after $24 \mathrm{~h}$ of the treatment. Nevertheless, the potential effect of the As on $\mathrm{Fe}$ cellular metabolism in this model could not be discarded. Besides the fact that arsenicals can release Fe by the activation of the enzyme HO-1 (Albores et al., 1989), as previously indicated, Fe is able to chelate As (Asghar and Zahra, 2017). This feature could be of significant relevance in terms of the establishment of oxidative-dependent damage to membranes since the exposure to the toxic could lead to modification of the cellular Fe distribution. Since the catalytic activity of $\mathrm{Fe}$ in the ROS metabolism strongly depends on the form in which the metal is present in the cell, the presence of a compound that could affect this scenario may act as a key factor to lead to oxidativedependent damage by increasing the content of the labile Fe pool (LIP).

\section{Conclusion:}

Taken as a whole, the information presented here showed new evidence on the generation of specific radical species by As treatment, both ex vivo and in vivo, and pointed out to the possibility that the triggering of some oxidative pathways (such as oxidation of GSH) occur accordingly to the via As reaches the brain, even achieving the same concentration of the toxic in the tissues. However, other pathways may be similarly affected under both conditions of treatment, since the oxidative balance in the lipophilic and hydrophilic medium followed the same pattern. On the other hand, further studies analyzing the effect of As exposure on the distribution of $\mathrm{Fe}$ in the brain cells, could be an important aspect to achieve a more specific knowledge on As-dependent ROS generation. Also, the effect of As exposure on nitrosative pathways may be explored to complete the knowledge of the oxidative scenario in the presence of As.

\section{Acknowledgments:}

This study was supported by grants from the University of Buenos Aires (20020130100383BA), the ANPCyT (PICT 00697) and CONICET (PIP 00845). SP is career investigator from CONICET and JGB is a fellow from CONICET.

\section{References:}

1. Ahmad, S., Kitchin, K.T., Cullen, W.R., 2000. Arsenic species that cause release of iron from ferritin and generation of activated oxygen. Arch. Biochem. Biophys. 382(2), 195-202.

2. Ahola, T., Fellman, V., Kjellmer, I., Raivio, K.O., Lapatto, R., 2004. Plasma 8-isoprostane is increased in preterm infants who develop bronchopulmonary dysplasia or periventricular leukomalacia. Ped. Res. 56, 88-93.

3. Albores, A., Cebrian, M.E., Bach, P.H., Connelly, J.C., Hinton, R.H., Bridges, J.W., 1989. Sodium arsenite induced alterations in bilirubin excretion and heme metabolism. J. Biochem. Toxicol. 4(2), 73-78. doi: $10.1002 /$ jbt. 2570040202

4. Aposhian, H.V., 1989. Biochemical toxicology of arsenic. Rev. Biochem. Toxicol. 10, 265-299.

5. Asghar, A., Zahra, M., 2017. Beneficial role of deferasirox and deferiprone in the mobilization of arsenic and recovery of iron in rat tissues. Main Group Chem. 16(1), 1-5. doi: 10.3233/MGC-160215

6. Aung, K.H., Kurihara, R., Nakashima, S., Maekawa, F., Nohara, K., Kobayashi, T., Tsukahara, S., 2013. Inhibition of neurite outgrowth and alteration of cytoskeletal gene expression by sodium arsenite. Neurotoxicology 34, 226-235. doi:10.1016/j.neuro.2012.09.008

7. Bharti, V.K., Srivastava, R.S., Sharma, B., Malik, J.K., 2012. Buffalo (Bubalusbubalis) epiphyseal proteins counteract arsenic-induced oxidative stress in brain, heart, and liver of female rats. Biol. Trace Elem. Res. 146(2), 224-229. doi: 10.1007/s12011-011-9245-0

8. Bonetto, J.G., Villaamil Lepori, E., Puntarulo, S., 2014. Update on the oxidative stress associated with arsenic exposure. Curr. Top. Toxicol. 10, 37-48.

9. Brumby, P.E., Massey, V., 1967. Determination of nonheme iron, total iron and cooper. Meth. Enzymol. 10, 463-474. 
10. Buettner, G.R., 1987. Spin trapping: ESR parameters of spin adducts. Free Radic. Biol. Med. 3, $259-303$.

11. Buettner, G.R., Jurkiewicz, B.A., 1993. Ascorbate free radical as a marker of oxidative stress: an EPR study. Free Radic. Biol. Med. 14, 49-55.

12. Catalayud, M., Devesa, V., Vélez, D., 2013. Differential toxicity and gene expression in Caco-2 cells exposed to arsenic species. Toxicol. Lett. 218(1), 70-80. doi: 10.1016/j.toxlet.2013.01.013

13. Chaudhuri, A.N., Basu, S., Chattopadhyay, S., Das Gupta, S., 1999. Effect of high arsenic content in drinking water on rat brain. Indian J. Biochem. Biophys. 36, 51-54.

14. Desai, I.D., 1984. Vitamin E analysis methods for animal tissues. Meth. Enzymol. 105, 138-146.

15. Drobna, Z., Xing, W., Thomas, D.J., Stýblo, M., 2006. shRNA silencing of AS3MT expression minimizes arsenic methylation capacity of HepG2 cells. Chem. Res. Toxicol. 19(7), 894-898. doi: 10.1021/tx060076u

16. European Communities Council Directives 24 November 1986 (86/609/EEC).

17. Garcia-Chavez, E., Santamaria, A., Diaz-Barriga, F., Mandeville, P., Juarez, B.I., Jimenez-Capdeville, M.E., 2003. Arsenite-induced formation of hydroxyl radical in the striatum of awake rats. Brain Res. 976(1), 82-89.

18. González, P.M., Abele, D., Puntarulo, S. 2012. A kinetic approach to assess oxidative metabolism related features in the bivalve Myaarenaria. Theory Biosci. 131(4), 253-264.

19. González, P.M., Aguiar, M.B., Malanga, G., Puntarulo, S., 2013. Electronic paramagnetic resonance (EPR) for the study of ascorbyl radical and lipid radicals in marine organisms. Comp. Biochem. Physiol. A 165(4), 439447.

20. Guide for the Care and Use of Laboratory Animals (National Academy of Sciences, NIH Publication 6-23, revised 1985).

21. Halliwell, B., 1994. Free radicals and antioxidans. Free radicals, antioxidants, and human disease: curiosity, cause, or consequence? Lancet 344, 721-724.

22. Hayakawa, T., Kobayashi, Y., Cui, X., Hirano, S., 2005. A new metabolic pathway of arsenite: arsenicglutathione complexes are substrates for human arsenic methyltransferase Cyt19. Arch. Toxicol. 79(4), 183191.

23. Jing, Y.K., Dai, J., Chalmers-Redman, R.M.E., Tatton, W.G., Waxman, S., 1999. Arsenic trioxide selectively induces acute promyelocytic leukemia cell apoptosis via a hydrogen peroxide-dependent pathway. Blood 94(6), 2102-2111.

24. Jomova, K., Jenisova, Z., Feszterova, M., Baros, S., Liska, J., Hudecova, D., Rhodesd, C.J., Valko, M., 2011. Arsenic: toxicity, oxidative stress and human disease. J. Appl. Toxicol. 31(2), 95-117. doi: 10.1002/jat.1649

25. Kharroubi, W., Haj Ahmed, S., Nury, T., Andreoletti, P., Sakly, R., Hammami, M., Lizard, G., 2017. Mitochondrial dysfunction, oxidative stress and apoptotic induction in microglial BV-2 cells treated with sodium arsenate. J. Environ. Sci. 51, 44-51. doi: 10.1016/j.jes.2016.08.028

26. Kotake, Y., Tanigawa, T., Tanigawa, M., Ueno, I., Allen, D.R., Lai, C., 1996. Continous monitoring of cellular nitric oxide generation by spin trapping with an iron-dithiocarbamate complex. Biochim. Biophys. Acta 1289 , 362-368.

27. Kutnink, M.A., Hawkes, W.C., Schaus, E.E., Omaye, S.T., 1987. An internal standard method for the unattended high-performance liquid chromatographic analysis of ascorbic acid in blood components. Anal. Biochem. 166, 424-430.

28. Lai, E.K., Crossley, C., Sridhar, R., Misra, H.P., Janzen, E.G., McCay, P.B., 1986. In vivo spin trapping of free radicals generated in brain, spleen, and liver during gamma radiation of mice. Arch. Biochem. Biophys. 244 , 156-160.

29. Laurie, S.H., Tancock, N.P., McGrath, S.P., Sanders, J., 1991. Influence of complexation on the uptake by plants of iron, manganese, copper and zinc: I. Effect of EDTA in a multimetal and computer simulation study. Exp. Bot. 42, 509-513.

30. Lin, S., Shi, Q., Nix, F.B., Styblo, M., Beck, M.A., Herbin-Davis, K.M., Hall, L.L., Simeonsson, J.B., Thomas, D.J., 2002. A novel S-adenosyl-L-methionine:arsenic(III) methyltransferase from rat liver cytosol. J. Biol. Chem. 277(13), 10795-10803. doi:10.1074/jbc.M110246200

31. Malanga, G., Pérez, A., Calvo, J., Puntarulo, S., 2009. The effect of seasonality on oxidative metabolism in the sea urchin Loxechinusalbus. Mar. Biol. 156, 763-770.

32. National Research Council. National Academy of Sciences, 2013. Critical Aspects of EPA's IRIS Assessment of Inorganic Arsenic: Interim Report. Committee on Inorganic Arsenic; Board on Environmental Studies and Toxicology; Division on Earth and Life Studies; https://www.nap.edu/read/18594/chapter/1.

33. Navoni, J.A., Olivera, N.M., Villaamil Lepori, E.C., 2010. Cuantificación de arsénicoporinyección en flujogeneración de hidruros-espesctrofotometría de absorciónatómica (IF-GH-EAA) previaderivatización con L- 
cisteína. Validación y comparaciónintermetodológicautilizando dos técnicas de referencia. Toxicol. Argent. Acta 18(2), 29-38.

34. Negishi, T., Matsunaga, Y., Kobayashi, Y., Hirano, S., Toshiro, T., 2013. The spectrum of circulating RNA: a window into systems toxicology. Toxicol. Sci. 132(2), 478-492. doi: 10.1093/toxsci/kft014

35. Pastore, A., Federicia, G., Bertinib, E., Piemonteb, F., 2003. Analysis of glutathione: implication in redox and detoxification. Clin. Chim. Acta 333(1), 19-39.

36. Piloni, N.E., Fermandez, V., Videla, L.A., Puntarulo, S, 2013. Acute iron overload and oxidative stress in brain. Toxicology 314(1), 174-182. doi: 10.1016/j.tox.2013.09.015

37. Rao, M.V., Avani, G., 2004. Arsenic induced free radical toxicity in brain of mice. Indian J. Exp. Biol. 42(5), 495-498.

38. Rezaei, M., Khodayar, M.J., Seydi, E., Soheila, A., Parsi, I.K., 2017. Acute, but not chronic, exposure to arsenic provokes glucose intolerance in rats: Possible roles for oxidative stress and the adrenergic pathway. Can. J. Diabetes 41(3), 273-280. doi: 10.1016/j.jcjd.2016.10.008

39. Rodríguez, V.M., Jiménez-Capdeville, M.E., Giordano, M., 2003. The effects of arsenic exposure on the nervous system. Toxicol. Lett. 145(1), 1-18.

40. Rodriguez-Ariza, A., Toribio, F., López-Barea, J., 1994. Rapid determination of glutathione status in fish liver using high-performance liquid chromatography and electrochemical detection. J. Chromatogr. B. Biomed. Appl. 656(2), 311-318.

41. Soria, E.A., Pérez, R.D., Queralt, I., Pérez, C.A., Bongiovanni, G.A., 2017. Immunotoxicological effects of arsenic bioaccumulation on spatial metallomics and cellular enzyme response in the spleen of male Wistar rats after oral intake. Toxicol. Lett. 266, 65-73. doi: 10.1016/j.toxlet.2016.12.014

42. Thomas, D.J., Styblo, M., Lin, S., 2001. The cellular metabolism and systemic toxicity of arsenic. Toxicol. Appl. Pharmacol. 176(2), 127-144. doi:10.1006/taap.2001.9258

43. Tolins, M., Ruchirawat, M., Landrigan, P., 2014. The developmental neurotoxicity of arsenic: cognitive and behavioral consequences of early life exposure. Ann. Globl. Health. 80(4), 303-314. doi: 10.1016/j.aogh.2014.09.005

44. Wang, T.S., Kuo, C.F., Jan, K.Y., Huang, H.M., 1996. Arsenite induces apoptosis in Chinese hamster ovary cells by generation of reactive oxygen species. J. Cell. Physiol. 169(2), 256-268. doi: 10.1002/(SICI)10974652(199611)169:2<256::AID-JCP5>3.0.CO;2-N

45. Wasserman, G.A., Liu, X., Loiacono, N.J., Kline, J., Factor-Litvak, P., van Geen, A., Mey, J.L., Levy, D., Abramson, R., Schwartz, A., Graziano, J.H., 2014. A cross-sectional study of well water arsenic and child IQ in Maine schoolchildren. Environ. Health 13(1), 23-33. doi: 10.1186/1476-069X-13-23.

46. Yamanaka, K., Hasegawa, A., Sawamura, R., Okada, S., 1989. Dimethylated arsenics induce DNA strand breaks in lung via the production of active oxygen in mice. Biochem. Biophys. Res. Commun. 165(1), 43-50.

47. Yamanaka, K., Kato, K., Mizoi, M., An, Y., Nakanao, M., Hoshino, M., Okada, S., 2009. Dimethylarsine likely acts as a mouse-pulmonary tumor initiator via the production of dimethylarsine radical and/or its peroxy radical. Life Sci. 84(17-18), 627-33.

48. Zamora, P.L., Rockenbauer, A., Villamena, F.A., 2014. Radical model of arsenic(III) toxicity: theoretical and EPR spin trapping studies. Chem. Res. Toxicol. 27(5), 765-774.

49. Zhang, T.L., Gao, Y.X., Lu, J.F., Wang, K., 2000. Arsenite, arsenate and vanadate affect human erythrocyte membrane. J. Inorg. Biochem. 79(1-4), 195-203. 